\title{
COMUNICACIÓN
}

\section{CONTAMINACIÓN DE PARQUES PÚBLICOS DEL CONO ESTE CON HUEVOS DE Toxocara spp.}

\author{
Marcos Serrano M. ${ }^{1}$, Amanda Chávez V. ${ }^{2}$ y Eva Casas A. ${ }^{2}$
}

\section{Abstract}

Toxocariasis has been recognized as an important zoonosis because the intake of infective Toxocara spp. eggs produces ocular migrant larva syndrome in humans, especially children. The objective of the present study was to evaluate the contamination of eastern Lima's public parks with Toxocara spp. eggs. Turf samples were collected from 151 of the 325 public parks using double W method during February and March 1999. Mean environmental temperature was $24.2^{\circ} \mathrm{C}$ with $81.5 \%$ relative humidity. Eggs were collected by flotation in supersaturated $\mathrm{NaCl}$ solution and subsequently incubated in $2.5 \%$ potassium dichromate solution for 30 days. Toxocara spp. egg contamination was found in 62 or $41.1 \% \pm 7.8 \%$ of the 151 parks studied. Classification of the parks according to the socio-economic status of their neighborhoods revealed contamination frequencies of $87.5,46.2,50.0,34.7$ and $37.1 \%$ for upper, upper-middle, middle, lowermiddle and lower class status respectively. Contamination rates of $92.3 \%, 44.7 \%$ and $7.7 \%$ were found for parks with good grass cover, moderate grass cover (around $50 \%$ covered with grass) and poor to non-existent grass cover, with an average of $3.04 \mathrm{eggs}$ per $100 \mathrm{~g}$ of sample. To test viability, four 3 three week old quails were infected with 1500 eggs and 4 controls were studied. Necropsies were performed at 24 hours, 5,10 and 15 days post-inoculation, and visceral larval migrants were collected using the Baerman technique from the liver, as well as heart, muscle, gizzard lungs and eyes. Clearly the Toxocara spp. contamination levels in eastern Lima's public parks represent a significant threat to public health, and it is imperative that local authorities implement appropriate regulations to eliminate this problem.

Key words: Ascariasis, Toxocara spp., Larval migrants, Zoonosis, Toxocariasis.

Palabras clave: Ascariasis, Toxocara spp, Larva migrante, Zoonosis, Toxocariasis.

El hombre está expuesto a zoonosis parasitarias, no sólo por el estrecho contacto con sus mascotas bajo condiciones sanitarias deficientes; sino también por el contacto con las heces de animales infectados.

\footnotetext{
I Práctica privada

2 Laboratorio de Parasitología IVITA - FMV . UNMSM.E.mail:d170010@unmsm.edu.pe.
}

La contaminación de los parques públicos con heces de perros infectados por Toxocara spp., es un problema de importancia en salud publica (Soulsby, 1987; Caseiro et al., 1995). La alta cantidad de huevos de Toxocara spp. diseminados por perros parasitados (Alcántara et al., 1989; Georgi y Georgi, 1994), que bajo adecuadas condiciones ambientales de temperatura, sombra y humedad se hacen infectivos 
(Beaver et al., 1984; Melhorn y Duwell, 1993), generan un alto riesgo para la población. La larva de Toxocara spp. es responsable del síndrome de larva migrante visceral (LMV) y ocular (Quiroz, 1990; Leguía, 1996; Moreira-Silva et al., 1998), presentándose con mayor frecuencia en niños por sus hábitos de jugar con tierra que puede estar contaminada con huevos de Toxocara spp (Genchi, 1990; Botero y Restrepo, 1998).

La costumbre de llevar mascotas a los parques públicos para que jueguen y realicen sus deposiciones, constituye el inicio de la instalación de una de las zoonosis de mayor riesgo en el hombre. En nuestro país, se han realizado algunos estudios sobre la contaminación de parques con huevos de Toxocara spp.; así, en 1975 Guerrero encontró en Lima una prevalencia del $24 \%$ de parques públicos contaminados. Recientemente Velarde (1999) y Cajas (1999) reportaron en distritos de la Provincia Constitucional del Callao y del Cono Sur de Lima Metropolitana 37 y $29 \%$ de parques contaminados con huevos de Toxocara spp., respectivamente.

El presente estudio evaluó la contaminación de parques de los distritos de AteVitarte, Chaclacayo, Cieneguilla, El Agustino, La Molina, San Juan de Lurigancho y Santa Anita, correspondientes al Cono Este de Lima Metropolitana, durante los meses de febrero y marzo de 1999 con una humedad relativa entre 79 y $84 \%$ y una temperatura promedio de 23.5 y $24.9^{\circ} \mathrm{C}$, respectivamente (Von Humbolt, 1999). Se colectaron muestras, entre 1 a $4 \mathrm{~kg}$ de tierra y césped según el método de la doble W; siendo procesadas por el método de flotación con solución sobresaturada de cloruro de sodio, considerándose positiva la muestra que presentaba al menos un huevo de Toxocara spp.
Los parques fueron agrupados de acuerdo al estado de conservación y al estrato socio económico del barrio. La clasificación según el estado de conservación fue: Bien conservados (césped en toda su área), medianamente conservados (césped en $50 \%$ del área) y mal conservados (sin césped en todo el área). Los lineamientos para la clasificación por estrato socio económico se hizo en base a directivas del Instituto Nacional de Estadística e Informática (INEI, 1998), considerando los siguientes niveles: estrato socio económico alto (Nivel I), medio alto (Nivel II), medio (Nivel III) medio bajo (Nivel IV) y bajo (Nivel V).

Los huevos obtenidos en el análisis coprológico fueron incubados en una solución de dicromato de potasio al $2.5 \%$ por 30 días con el fin de obtener huevos larvados. Estos, en número de 1,500 fueron inoculados vía oral en 8 codornices, las que fueron sacrificadas al cabo de 24 horas, 5,10 y 15 días post inoculación, respectivamente, para determinar lesiones macroscópicas e histopatológicas. Asimismo, se tomaron muestras para la estimación de larvas migrantes mediante la técnica de Baerman.

El tamaño muestral de 151 parques se determinó con la fórmula para proporciones en poblaciones finitas (Daniel, 1996), posteriormente se estratificó el número de parques a muestrear por distrito, siendo todos ellos seleccionados al azar. Los resultados son expresados en forma porcentual, calculándose sus respectivos intervalos de confianza, a través de la aproximación normal a la binomial.

El $41.1 \%$ de los parques del Cono Este de Lima Metropolitana se encuentran contaminados con huevos de Toxocara spp. Distritos como La Molina y San Juan de Lurigancho presentaron frecuencias de 
contaminación superiores al 45\% (Cuadro 1).

En relación con el estado de conservación de los parques, el mayor porcentaje de parques positivos fueron los parques clasificados como bien y medianamente conservados; mientras que los parques clasificados como mal conservados fueron los menos contaminados (Cuadro 2).

Estos resultados se atribuyen al hecho de que los parques bien y medianamente conservados tienen áreas con vegetación, que proporcionan factores como humedad y sombra, que favorecen la sobrevivencia y evolución de los huevos. Por otro lado, en los parques mal conservados los huevos están expuestos a los rayos solares que en corto tiempo los destruyen.

Respecto al estrato socio económico, en los Niveles I y II se encuentran los mayores porcentaje de parques contaminados con huevos de Toxocara spp, en tanto que el menor grado de contaminación ocurrió en el Nivel IV (Cuadro 3).

En los niveles I y II se observaron un elevado porcentaje de parques contaminados; por contar con una mayor cantidad de parques en buen estado de conservación; mientras que en los niveles IV y $\mathrm{V}$ el porcentaje de contaminación fue bajo debido a lo mal conservado que están los parques en estos niveles y que a pesar de presentar huevos de Toxocara spp, por la alta cantidad de perros, éstos son destruidos probablemente por la acción directa de los rayos solares.

Otros factores que favorecen su elevada presentación en parques, serían la alta prevalencia del parásito en perros y gatos de Lima Metropolitana (Leguía, 1996 y Díaz 1999). Así mismo se señala el gran potencial biótico de las hembras de $T$. canis que pueden liberar hasta 200,000 huevos por día, los que pueden eliminarse via heces (Soulsby, 1987; Cordero et al. 1999); la alta densidad de perros/persona existente en Lima Metropolitana, aproximadamente de 6:1 (Effio, 1999); además, del reducido número de mascotas con desparasitaciones periódicas son factores que favorecen también esta prevalencia.

Adicionalmente, se evaluó la cantidad de huevos de Toxocara spp. presentes en $100 \mathrm{~g}$ de muestra de los parques positivos, encontrándose un promedio de 3 huevos.

Cuadro 1. Distribución de parques contaminados con huevos de Toxocara spp. según Distritos en Lima.

\begin{tabular}{lccc}
\hline Distritos & Total de parques & \multicolumn{2}{c}{ Parques positivos } \\
\cline { 3 - 4 } & $\mathrm{n}$ & $\mathrm{n}$ & $\% \pm \mathrm{IC}$ \\
\hline Ate Vitarte & 38 & 14 & $36.8 \pm 15.3$ \\
Chaclacayo & 10 & 2 & 20.0 \\
Cieneguilla & 7 & 1 & 14.3 \\
El Agustino & 13 & 5 & 38.5 \\
La Molina & 34 & 19 & $55.9 \pm 16.7$ \\
Sn Juan de Lurigancho & 33 & 15 & $45.5 \pm 17.0$ \\
Santa Anita & 16 & 6 & 37.5 \\
\hline Total & 151 & 62 & $41.1 \pm 7.8$ \\
\hline
\end{tabular}


Cuadro 2. Distribución de parques en Lima contaminados con huevos de Toxocara spp. de los distritos del Cono Este según estado de conservación.

\begin{tabular}{lccc}
\hline Estado de conservación & Total de parques & \multicolumn{2}{c}{ Parques positivos } \\
\cline { 3 - 4 } & $\mathrm{n}$ & $\mathrm{n}$ & $\% \pm \mathrm{IC}$ \\
\hline Bien conservados & 39 & 36 & $92.3 \pm 8.4$ \\
Medianamente conservados & 47 & 21 & $44.7 \pm 14.2$ \\
Mal conservados & 65 & 5 & $7.7 \pm 6.5$ \\
\hline Total & 151 & 62 & $41.1 \pm 7.8$ \\
\hline
\end{tabular}

Cuadro 3. Distribución de parques contaminados de los distritos del Cono Este de Lima con huevos de Toxocara spp. según estrato socioeconómico.

\begin{tabular}{llcc}
\hline $\begin{array}{l}\text { Estrato socio- } \\
\text { económico }^{1}\end{array}$ & Distritos & $\begin{array}{c}\text { Total de parques, } \\
\mathrm{n}\end{array}$ & $\begin{array}{c}\text { Parques } \\
\text { contaminados, } \\
\% \pm \text { IC }\end{array}$ \\
\hline Nivel I & La Molina & 8 & 87.5 \\
Nivel II & La Molina & 26 & 46.2 \\
Nivel III & $\begin{array}{l}\text { Cieneguilla, Chaclacayo, } \\
\text { Ate Vitarte, El Agustino. }\end{array}$ & 6 & 50 \\
Nivel IV & $\begin{array}{l}\text { S.J. de Lurigancho, } \\
\text { Santa Anita }\end{array}$ & 49 & $34.7 \pm 13.3$ \\
Nivel V & $\begin{array}{l}\text { Ate Vitarte, Chaclacayo, } \\
\text { Cieneguilla, El Agustino, }\end{array}$ & & \\
& S.J. Lurigancho y Sta. Anita & 62 & $37.1 \pm 12.0$ \\
\hline Total & & 151 & $41.1 \pm 7.8$ \\
\hline
\end{tabular}

Fuente: Instituto Nacional de Estadística e Informática (INEI). (1998).

También se observó que los distritos con elevado número de perros (San Juan de Lurigancho y El Agustino) tienden a presentar mayor densidad de huevos de Toxocara spp.(Cuadro 4).

Se aislaron larvas migrantes de corazón, hígado, músculos, proventrículo, pulmones y ojos de las codornices inoculadas comprobandose la vialidad de los huevos. Así mismo, se observaron larvas enquistadas en el parénquima hepático a los 10 días de inoculación; así como lesiones de una infección de tipo aguda.

Se concluye que existe una alta prevalencia de parques públicos contaminados con huevos de Toxocara spp. de los distritos del Cono Este de Lima. Por lo que resulta un riesgo latente y alto para la población que frecuentan estos parques públicos. Lamentablemente, esta zoonosis no es de notificación obligatoria y no se lleva un registro de casos. Por este motivo, se 
Cuadro 4. Promedio de huevos de Toxocara spp. encontrados en muestras de $100 \mathrm{~g}$ de tierra de los parques positivos del Cono Este de Lima según estado de conservación.

\begin{tabular}{lcccc}
\hline Distritos & $\begin{array}{c}\text { Bien } \\
\text { conservados }\end{array}$ & $\begin{array}{c}\text { Medianamente } \\
\text { conservados }\end{array}$ & $\begin{array}{c}\text { Mal } \\
\text { conservados }\end{array}$ & Total \\
\hline Ate Vitarte & 4.7 & 3.5 & 1.0 & 3.9 \\
Chaclacayo & 1.0 & 0 & 0 & 0.5 \\
Cieneguilla & 1.0 & 0 & 0 & 1.0 \\
El Agustino & 7.0 & 4.5 & 0 & 4.6 \\
La Molina & 1.1 & 0 & 0 & 1.0 \\
San Juan de Lurigancho & 9.5 & 3.4 & 0.5 & 4.7 \\
Santa Anita & 6.5 & 2.0 & 0 & 3.2 \\
\hline Total & 3.3 & 3.2 & 0.4 & 3.0 \\
\hline
\end{tabular}

recomienda iniciar una campaña cívica y de educación sanitaria dirigida a padres, profesores y niños, así como a dueños de mascotas. Por otro lado, se debe informar a las autoridades municipales y sanitarias del peligro potencial de esta zoonosis y tomar medidas a fin de reducir al mínimo la incidencia de esta zoonosis. También se recomienda desparasitaciones periódicas de las mascotas y control de animales vagabundos, y una legislación sanitaria sobre tenencia y circulación de perros en nuestra comunidad.

\section{Literatura Citada}

1. Alcántara, N.; E. Bavia y R.M. Silvao. 1989. Environmental contamination by Toxocara spp. eggs in public areas of Salvador, Bahia State, Brasil. Rev Soc Bras Med Trop. 22(4): 187-90.

2. Beaver, P.C.; R.C. Jung y E.W. Cupp. 1984. Clinical Parasitology. $9^{\text {th }}$ Edit.p: 320-24 Lea y Febiger, Philadelphia.

3. Botero, D. y M. Restrepo. 1998. Parasitosis Humanas. Corporación para investigaciones biológicas. Medellín,
Colombia.: 309-12.

4. Cajas, J.C. 1999. Contaminación de los parques públicos con huevos de Toxocara spp. en los Distritos del Cono Sur (Chorrillos, San Juan de Miraflores, Villa María del Triunfo y Villa El Salvador). Tesis Médico Veterinario. FMVUNMSM. 67p.

5. Caseiro, M.; P. Chieffi; M. Ruivo y L. Cagliani. 1995. Soil contamination by Toxocara spp. eggs in squares of Santos, Sao Paulo state, Brasil. Rev Soc Chil Parasitol. 19(360).

6. Cordero, M.; F. Rojo; B. Díez y P. Morrondo. 1999. Parasitología Veterinaria. 1ra. Ed. p:636-642. McGraw - hill - Interamericana. España.

7. Daniel, W. 1996. Bioestadística. Base para el análisis de las ciencias de la salud. 3ra. Ed., p:206. Editorial LIMUSA S.A. México.

8. Díaz, P. 1999. Comparación de dos métodos convencionales de diagnóstico de nemátodes intestinales en Canis familiaris, con el examen post-mortem. Tesis Médico Veterinario. FMVUNMSM. 40 p.

9. Effio, T. J. 1999. Estudio preliminar del mercado Veterinario Peruano 
INDECOPI. Lima-Perú. 258 p.

10. Genchi, C. 1990. Pruebas de campo sobre la eficacia del nitroscanato y mebendazol como antihelminticos en el perro. The Veterinary Record. 126:7780.

11. Georgi, J. R. y M.E. Georgi. 1994. Parasitología en Clínica Canina. Ed. Interamericana. p.155-159. México.

12. Guerrero, M.O. 1975. Estudio de la contaminación de parques públicos de Lima Metropolitana con huevos de Toxocara spp. Tesis Médico Veterinario. FMV-UNMSM. Lima-Perú. 12 p.

13. Instituto Nacional de Estadística e Informática (INEI). 1998. Planos estratificados de Lima Metropolitana a nivel de manzana, según estrato socioeconómico de los hogares. $150 \mathrm{p}$.

14. Leguía, G. P. 1996. Enfermedades parasitarias de perros y gatos. Epidemiología y Control. P: 10-19. Editorial del Mar E.I.R. Lima - Perú.

15. Melhorn, M. y D. Duwell. 1993. Manual de parasitología Veterinaria. 1ra. Ed. p:35-37. Presencia Ltda. Grass- latros. p.436. Colombia.

16. Moreira-Silva, S.F.; M.E. Leao; H.F. Mendonca y F.E. Pereira. 1998. Prevalence of anti-Toxocara antibodies in a random sample of inpatients at a children's Hospital in vitoria, Espirito Santo, Brazil. Rev Vet Med Trop Sao Paulo. 40(4): 259-61.

17. Quiroz, H. 1990. Parasitología y enfermedades parasitarias de animales domésticos 2da. Ed. p: 404-412. Editorial Limusa S.A. México.

18. Soulsby, E. J. 1987. Parasitología y enfermedades parasitarias de los animales domésticos. $7^{\circ}$ Ed., p:150-155. Nueva Editorial Interamericana S.A. México.

19. Velarde, J.A. 1999. Contaminación de los parques públicos de la Provincia Constitucional del Callao con huevos de Toxocara spp. Tesis Médico Veterinario. FMV- UNMSM. 50p.

20. Von, Humbolt. 1999. Estación Metereología de la Universidad Agraria - La Molina. Institución donde se obtuvo la información clímatica de los Distritos del Cono Este. 